\title{
ADEQUAÇÃO DO LAYOUT DE UMA FÁBRICA DE FERRAMENTAS FLORESTAIS BASEADO EM PARÂMETROS ERGONÔMICOS
}

\author{
Pompeu Paes Guimarães ${ }^{1}$, Nilton César Fiedler ${ }^{2}$, Flávio Cipriano de Assis do Carmo ${ }^{3}$, \\ José Tarcísio da Silva Oliveira ${ }^{2}$, Luciano José Minette ${ }^{4}$, Rômulo Maziero ${ }^{5}$, Leidimari Neves do Prado ${ }^{6}$ \\ ${ }^{1}$ Eng. Florestal, Doutorando em Eng. Florestal, UFPR, UFERSA, Mossoró, RN, Brasil - pompeu.guimaraes@ufersa.edu.br \\ ${ }^{2}$ Eng. Florestal, Dr., UFES, Alegre, ES, Brasil - nilton.fiedler@ufes.br; jtsilva@npd.ufes.br \\ ${ }^{3}$ Eng. Florestal, Doutorando em Ciências Florestais, UFES, Alegre, ES, Brasil - flaviocipriano@ hotmail.com \\ ${ }^{4}$ Eng. Florestal, Dr., Depto. de Engenharia Elétrica e Mecânica, UFV, Viçosa, MG, Brasil - minetti@ufv.br \\ ${ }^{5}$ Eng. Industrial Madeireiro, UFES, Alegre, ES, Brasil - maziero.ufes@ gmail.com \\ ${ }^{6}$ Eng $^{\text {a }}$. Florestal, Mestranda em Engenharia Florestal, UFPR, Curitiba, PR, Brasil - leidimari_prado@hotmail.com \\ Recebido para publicação: 17/09/2012 - Aceito para publicação: 25/09/2013
}

\begin{abstract}
Resumo
Esta pesquisa avaliou os postos de trabalho em uma fábrica de produção de ferramentas florestais visando otimizar as condições ergonômicas e o layout do processo de produção baseado nos parâmetros ergonômicos e de produtividade. Para analisar o conforto térmico, foi utilizado o índice de bulbo úmido termômetro de globo (IBUTG); para medir a velocidade do vento, anemômetro; luxímetro para avaliar a quantidade de luz do galpão de produção; e decibelímetro, para coletar o ruído a que os trabalhadores estavam expostos. O posicionamento de todas as máquinas foi mensurado junto com o caminhamento no processo de produção, sendo realizado estudo de tempos, movimentos e de produtividade. De acordo com os resultados, a área das forjadoras 1 e 2 apresentou valores de IBUTG acima do limite permitido de $25^{\circ} \mathrm{C}$. A velocidade do vento em todas as atividades foi menor que $0,75 \mathrm{~m} / \mathrm{s}$ e apenas a região do orvado, área de corte 1 e soldagem apresentaram níveis de iluminância acima do mínimo permitido (NR-15). Todas as atividades extrapolaram os níveis de ruído toleráveis para a atividade, exceto o envernizamento. Pela análise do layout, propõe-se uma nova disposição física, para reduzir os tempos improdutivos, melhorar as condições ergonômicas e facilitar a sequência de produção e escoamento dos produtos.

Palavras-chave: Ergonomia; arranjo físico; produção de ferramentas.
\end{abstract}

\begin{abstract}
Layout adequacy of a forestry tool factory for ergonomic parameters. This research evaluated the work in a forestry tools factory in order to optimize ergonomic condition and layout of production process based on ergonomic parameters and productivity. Different methods had been used to analyze the factory environment as the Wet Bulb Globe Thermometer Index (WBGT), to analyze thermal comfort, the anemometer, to measure the wind speed, the lux meter, to assess the amount of light inside the production building, and decibel meter, to collect the workers exposure to noise. The placement of all the machines was measured along the development pathway of the production process, and studies of time, movements and productivity had been developed. According to the results, the area of forger 1 and 2 had values above the allowable WBGT limit of $25{ }^{\circ} \mathrm{C}$. The wind speed in all activities was less than $0.75 \mathrm{~m} / \mathrm{s}$ and only the region of orvado, welding and cutting area 1 presented illumination levels over the minimum allowed (NR-15). Noise levels extrapolated in all the activities but varnishing. As result, it proposes a new physical layout in order to reduce unproductive times, improve the ergonomic conditions, and facilitate production sequence as well as materials flow.

Keywords: Ergonomics; physical arrangement; tool production.
\end{abstract}

\section{INTRODUÇÃO}

No processo de fabricação de várias ferramentas utilizadas no setor florestal, são confeccionadas peças por intermédio do processo de forjamento por martelamento. Esse processo é constituído por 
pancadas sucessivas com golpes ou batidas rápidas no metal, aplicando pressão sobre as peças no momento em que existe o contato do martelo da forjadora e a peça metálica (GUIMARÃES, 2011).

A ergonomia do ambiente construído, também conhecida como ergonomia ambiental, corresponde a mais uma vertente que se insere nas pesquisas da relação do ser humano com o ambiente, a partir dos aspectos sociais, psicológicos, culturais e organizacionais (VASCONCELOS et al., 2009).

Um layout ergonômico oferece um posicionamento e orientação de locais de trabalho individual em um determinado espaço de trabalho, facilitando o fluxo das atividades e a cooperação entre pessoas internas e externas ao empreendimento. Garante também a privacidade necessária dos setores de trabalho, assegura a iluminância necessária que a tarefa demanda, uniformemente em todos os setores e sem reflexo, e evita a ocorrência de calor ou frio drástico, permitindo acessos livres e seguros às estações de trabalho (MARMARAS; NATHANAEL, 2006).

Layout, na literatura inglesa, é o termo que designa arranjo físico em português. Segundo Correa e Correa (2008), é a maneira pela qual os recursos que ocupam espaço dentro de uma operação encontram-se dispostos fisicamente. Existem três tipos básicos de arranjos físicos: por processo ou funcional - agrupam-se recursos com função ou processo similar; por produto ou em linha - a ordem lógica para arranjar a posição relativa dos recursos é a sequência de etapas do processo de agregação de valor; e posicional - os recursos é que se deslocam até o operador.

Sabe-se que os recursos de muitas organizações são destinados primeiramente a equipamentos e instalações físicas e que grande parte dos custos de produção está relacionada ao material, às pessoas ou ao fluxo de trabalho. A importância da distribuição física de uma empresa é reforçada pelas consequências em longo prazo das decisões e do custo de reprojetar a planta. Assim, um layout inicial correto é fundamental para a efetividade e eficiência operacional de uma empresa (URBAN, 1989, apud TORTORELLA; FOGLIATTO, 2008).

Segundo Silva et al. (2006), os parâmetros antropométricos dos trabalhadores devem ser levados em consideração no dimensionamento de postos de trabalho nas marcenarias. Fiedler et al. (2009) estudaram a conformação da distribuição física das máquinas comumente utilizadas nas marcenarias do sul do estado do Espírito Santo, propondo novos layouts do processo produtivo da atividade de produção de móveis. Esses autores recomendaram pequenas mudanças, devido às marcenarias analisadas serem de pequeno porte e inviáveis a mudanças drásticas no processo produtivo.

Esta pesquisa objetiva avaliar o layout do processo produtivo de uma empresa de ferramentas florestais e propor um novo layout, otimizado por meio de parâmetros ergonômicos, a fim de melhorar o sistema de produção da empresa.

\section{MATERIAL E MÉTODOS}

\section{Caracterização do local de estudo}

Os dados da pesquisa foram coletados no galpão de produção de uma empresa de ferramentas no sul do estado do Espírito Santo, no município de Marechal Floriano (latitude $20^{\circ} 24^{\prime}$ e longitude $40^{\circ} 37^{\prime}$ ). A precipitação média do município é de $1.572,2 \mathrm{~mm}$. O clima predominante é o tropical de altitude, com temperatura média de $17,5^{\circ} \mathrm{C}$, máxima de $32{ }^{\circ} \mathrm{C}$ e mínima de $3{ }^{\circ} \mathrm{C}$ (ASSOCIAÇÃO NACIONAL DAS ÁGUAS (ANA), 2010). As avaliações foram feitas nos postos de trabalho durante o processo de produção das ferramentas da empresa (Tabela 1). Ao todo, são confeccionados 39 modelos de ferramentas, produzidas com matéria-prima feita de barras de aço de carbono.

\section{População e amostragem}

Primeiramente, foi realizado um estudo-piloto, para definir o tamanho mínimo das amostras de níveis de conforto térmico, iluminação, ruído e ventilação a serem coletados durante a pesquisa, por meio da equação proposta por Conaw (1977).

$$
\mathrm{n} \geq \frac{\mathrm{t}^{2} * \mathrm{~s}^{2}}{\mathrm{e}^{2}}
$$

Em que: "n": número mínimo de amostras necessárias;

"t": valor tabelado a 10\% de probabilidade (distribuição t de Student); 
"s": desvio padrão das amostras;

"e": erro admissível a $10 \%$ em torno da média.

\section{Descrição da atividade}

Na tabela 1 e figura 1 são caracterizadas as atividades que compõem o processo de fabricação de ferramentas.

Tabela 1. Atividades que compõem o processo de produção de ferramentas.

Table 1. Activities that comprise the production process tools.

Área de corte 1: O operador mede a barra de aço e a secciona, com o uso da máquina de corte. A lâmina de corte da máquina fica perpendicular a barra de aço e serve para reduzir o comprimento da mesma para o tamanho correto da ferramenta.

Área de corte 2: O operador mede a barra de aço e a secciona, com o uso da máquina de corte. A lâmina de corte da máquina fica paralela à barra de aço e serve para reduzir sua largura para o tamanho correto da ferramenta.

Região de orvado: Faz-se a extremidade da barra de aço adquirir formato cilíndrico para encaixe do cabo da ferramenta. Primeiro a barra de aço é aquecida e prensada, de forma que fique cilíndrica. Contém as seguintes máquinas: três forjadoras 1 que aumentam as dimensões da barra de aço em comprimento e quatro prensas excêntricas que modelam a superfície de aço em formas cilíndricas.

Soldagem: É um processo que visa a união localizada de materiais de forma permanente. A solda é utilizada para unir a superfície cilíndrica da peça feita na região do orvado.

Área de viragem: Etapa utilizada para fazer superfícies curvas no maior comprimento da barra de aço (ex.: faz a angulação da foice). Utiliza as seguintes máquinas: duas prensas e uma forjadora 2.

Área da forjadora 1: Máquina que, por pancadas sucessivas, aplica pressão sobre as peças. É utilizada para alongar ("esticar") as dimensões da barra de aço em seu comprimento. Ao todo, nesta etapa são utilizadas três prensas, três forjadoras $1 \mathrm{e}$ uma forjadora 2.

Área da forjadora 2: Depois de forjada, a peça é marcada, ou seja, por pancadas sucessivas aplica-se pressão sobre as peças, para fazer um melhor acabamento de sua superfície (alisamento). Ao todo, nesta etapa são utilizadas quatro máquinas.

Têmpera: As peças são aquecidas em fornos e em seguida são imersas em banho de óleo frio, potencializando a durabilidade e resistência à superfície de corte da peça. Na têmpera, o trabalhador fica com a peça diretamente sobre fogo (têmpera aberta) e em seguida golpeia a peça com uma marreta em cima de uma bigorna.

Esmeril: Máquina utilizada para afiar as lâminas das peças em geral e acabamentos finais dos cabos de facas. Ao todo, são onze esmeris, trabalhando um ou dois acertadores por máquina.

Inserção de cabos: Fase em que é acrescida a lâmina de corte (faca, facão e cutelo) à superfície para pega.

Envernizamento - Mesa de acabamento final, onde as peças são envernizadas e é afixado o emblema da empresa.

\section{Conforto térmico}

As condições climáticas do ambiente de trabalho foram avaliadas com o uso de um termômetro digital de índice de bulbo úmido termômetro de globo (IBUTG), da marca Metrosonics, modelo HS 3600. As leituras foram feitas de hora em hora, durante a jornada de trabalho, em cada posto de trabalho na empresa, sendo a primeira leitura feita às $8 \mathrm{~h}$ e a última às $17 \mathrm{~h}$. Os valores obtidos foram comparados com os valores máximos permitidos pela legislação vigente (NR 15 - MINISTÉRIO DO TRABALHO E DO EMPREGO (MTE), 2009), conforme apresentado na tabela 2.

Tabela 2. Regime de trabalho devido ao tipo de atividade.

Table 2. Work regime due to the type of activity.

\begin{tabular}{lccc}
\hline Regime de trabalho intermitente com descanso no & \multicolumn{3}{c}{ Tipo de atividade } \\
\cline { 2 - 4 } próprio local de trabalho (por hora) & Leve & Moderada & Pesada \\
\hline Trabalho contínuo & até $30,0{ }^{\circ} \mathrm{C}$ & até $26,7{ }^{\circ} \mathrm{C}$ & até $25,0{ }^{\circ} \mathrm{C}$ \\
\hline $\begin{array}{l}45 \text { minutos trabalho } \\
15 \text { minutos descanso }\end{array}$ & 30,1 a $30,5{ }^{\circ} \mathrm{C}$ & 26,8 a $28,0{ }^{\circ} \mathrm{C}$ & 25,1 a $25,9{ }^{\circ} \mathrm{C}$ \\
\hline $\begin{array}{l}30 \text { minutos trabalho } \\
30 \text { minutos descanso }\end{array}$ & 30,7 a $31,4{ }^{\circ} \mathrm{C}$ & 28,1 a $29,4{ }^{\circ} \mathrm{C}$ & 26,0 a $27,9{ }^{\circ} \mathrm{C}$ \\
\hline $\begin{array}{l}15 \text { minutos trabalho } \\
45 \text { minutos descanso }\end{array}$ & 31,5 a $32,2{ }^{\circ} \mathrm{C}$ & 29,5 a $31,1{ }^{\circ} \mathrm{C}$ & 28,0 a $30,0{ }^{\circ} \mathrm{C}$ \\
\hline $\begin{array}{l}\text { O trabalho não é permitido sem a adoção de medidas } \\
\text { adequadas de controle }\end{array}$ & acima de $32,2{ }^{\circ} \mathrm{C}$ & acima de $31,1{ }^{\circ} \mathrm{C}$ & acima de $30,0{ }^{\circ} \mathrm{C}$ \\
\hline
\end{tabular}

FLORESTA, Curitiba, PR, v. 43, n. 4, p. 515 - 524, out. / dez. 2013.

Guimarães, P. P. et al. 


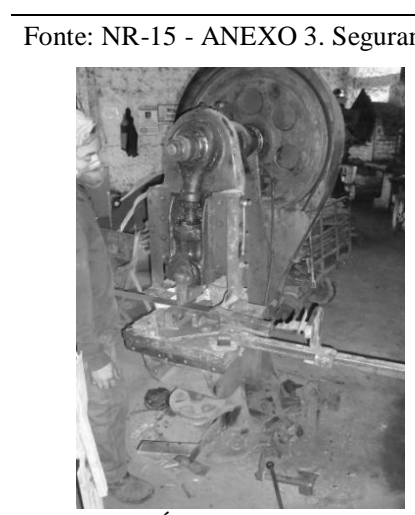

Área de corte 1

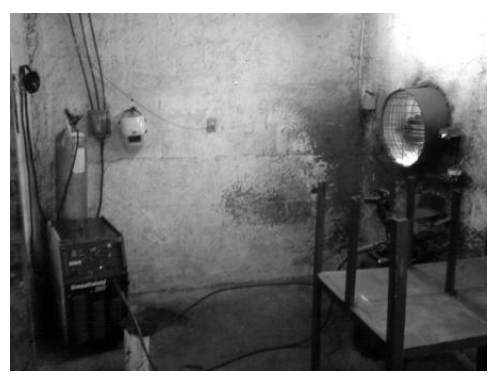

Soldagem

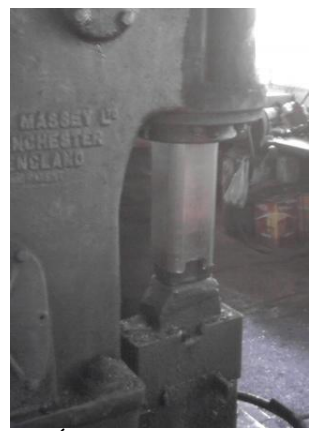

Área da forjadora 2

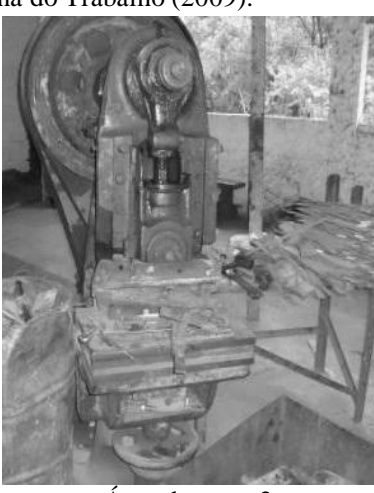

Área de corte 2

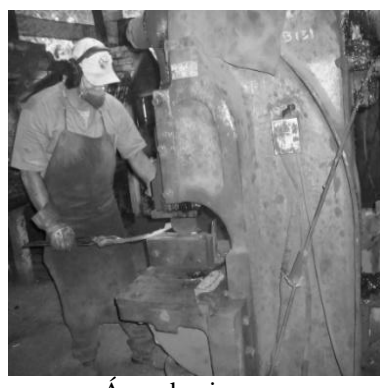

Área de viragem

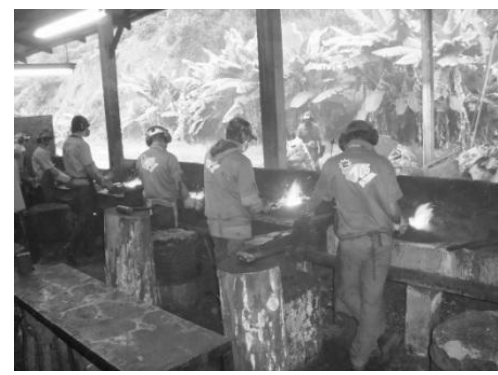

Têmpera

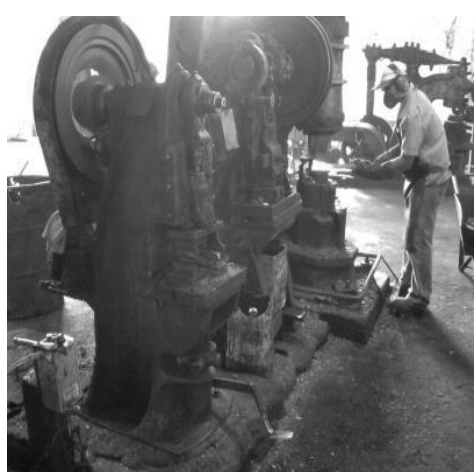

Região de orvado

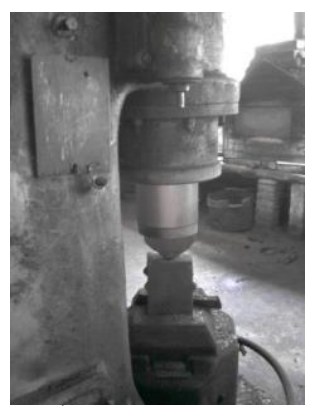

Área da forjadora 1

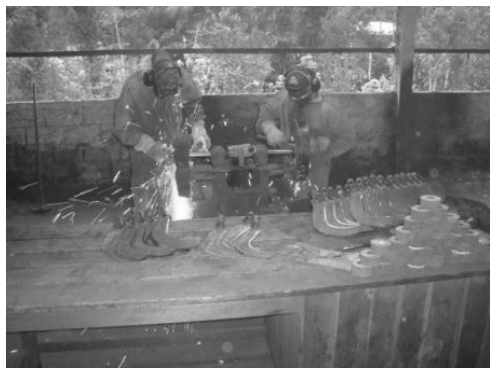

Esmeril

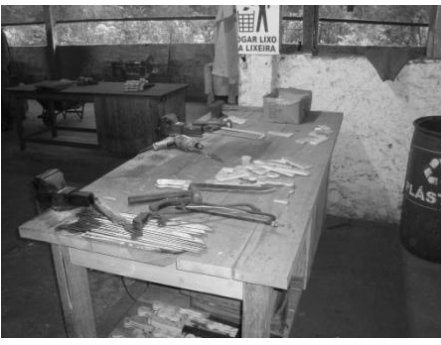

Inserção de cabos

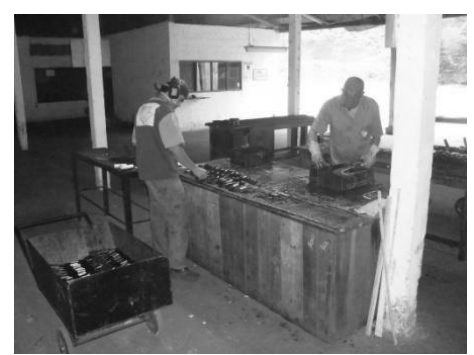

Envernizamento

Figura 1. Máquinas utilizadas para a produção de ferramentas florestais.

Figure 1. Machines used for the production of forestry tools.

\section{Ventilação}

Na coleta da ventilação, foi utilizado um anemômetro digital modelo MDA - II da marca Minipa, para medir a velocidade do vento em cada atividade do processo de produção de ferramentas. Segundo a 
NR 17 (MTE, 2006), para atividades leves, a velocidade máxima do vento deve ser de $0,75 \mathrm{~m} / \mathrm{s}$, e para ambientes com fontes de calor ou trabalhos pesados, essa velocidade pode subir até $1,5 \mathrm{~m} / \mathrm{s}$.

\section{Iluminância}

A iluminância foi medida com luxímetro digital portátil marca TES, modelo TES1332A, com leituras também feitas sistematicamente a cada hora de trabalho (conforme NBR 5413/92), na altura da bancada onde cada máquina era manuseada. Segundo essa legislação, em usinas de aço que trabalham com forjadoras e salas de máquinas há necessidade de intensidade de iluminação mínima entre 150 e 300 lux.

\section{Níveis de ruído}

O ruído foi medido com o uso de um decibelímetro digital de marca Instrutherm, modelo DEC 460, com sensor posicionado próximo ao nível do ouvido do trabalhador enquanto operava a máquina, conforme a norma NR15 (MTE, 2006). As leituras foram feitas de hora em hora, durante toda a jornada de trabalho, sendo os valores $(\mathrm{dB}(\mathrm{A}))$ lidos e anotados para posteriormente ser feita uma média do nível de ruído no ambiente de trabalho da respectiva máquina.

Os limites de tolerância para ruído contínuo ou intermitente devem obedecer à NR-15 (anexo $\mathrm{n}^{\mathrm{o}}$ 1, Portaria $\mathrm{n}^{\circ}$ 3.214/78, MTE), sendo que, acima de $85 \mathrm{~dB}(\mathrm{~A})$, para cada $5 \mathrm{~dB}(\mathrm{~A})$ acrescidos deve-se reduzir a jornada de trabalho à metade da exposição diária permitida (8 horas de trabalho).

\section{Layout do ambiente de trabalho}

Para adequação do processo produtivo, os postos de trabalho foram dimensionados com o auxílio de uma trena de 50 metros, assim como as máquinas alocadas para confecção da planta baixa do galpão de produção de ferramentas. Além disso, avaliou-se a sequência lógica de trabalho dos operadores por atividade em relação ao posicionamento de cada máquina no galpão. Essa análise foi utilizada para a proposta de intervenção e elaboração de um layout adequado, respeitando as especificações do fluxo de produção, sendo utilizado para essa análise o software AutoCAD 2007.

\section{Procedimento estatístico}

Os dados dessas variáveis (conforto térmico, ventilação, iluminação e ruído) foram analisados por meio de um delineamento inteiramente casualizado, constando de 11 tratamentos (máquinas analisadas) e número de repetições de 200 amostras para cada variável. Após a coleta de dados, foi realizada uma análise de variância, e quando diferenças estatísticas foram observadas, foi aplicado o teste de Scott-Knott ao nível de 5\% de probabilidade.

\section{RESULTADOS E DISCUSSÕES}

A tabela 3 e a figura 2 indicam os valores médios, o desvio padrão e o número mínimo de amostras necessárias para IBUTG, ventilação, iluminância e ruído, durante a jornada de trabalho. Foram coletadas 200 amostras para cada uma das variáveis mensuradas, sendo que essa quantidade foi representativa para caracterizar a população do ambiente de trabalho, conforme realização do estudopiloto, em relação ao conforto térmico, ventilação, iluminância e ruído.

A produção de ferramentas é uma atividade classificada como pesada, pois o trabalho de levantar, empurrar ou arrastar pesos é intermitente (anexo $n^{\circ} 3$ da Portaria $\mathrm{n}^{\circ} 3.214 / 78$, do MTE). Com uma jornada de trabalho realizada continuamente nessas condições, deve-se ter um ambiente com um IBUTG de até $25{ }^{\circ} \mathrm{C}$. As atividades da área da forjadora 1 e 2 apresentaram valores superiores estatisticamente aos das demais máquinas ao nível de 5\% de probabilidade, resultando em desconforto térmico. Desse modo, deve-se trabalhar por 45 minutos e descansar por 15 minutos.

Em relação à ventilação, todas as atividades apresentam conforto, pois os valores encontrados, não ultrapassaram o limite de conforto especificado pela NR-17 (máximo 1,5 m/s). A área de soldagem apresentou a menor média pelo teste de Scott-Knott.

Os níveis de iluminância adequados foram encontrados nas atividades da região do orvado, área de corte 1 e soldagem. $\mathrm{Na}$ área de corte 2 aconteceu um excesso de iluminância, comprovado pela análise estatística, que pode provocar ofuscamentos e/ou falta de atenção durante a realização dessa atividade. Em 
todas as outras funções, o nível de iluminância estava abaixo do limite adequado, necessitando o acréscimo de mais lâmpadas para que essas atividades apresentem os níveis mínimos recomendados (150 Lux).

Tabela 3. Média, desvio padrão e número mínimo de amostras para conforto térmico, ventilação, iluminação e ruído em cada atividade, ao teste de Scott-Knott no nível de 5\% de probabilidade.

Table 3. Average, standard deviation and minimum number of samples for thermal comfort, ventilation, lighting and noise in each activity, due to the Scott-Knott test, at 5\% probability.

\begin{tabular}{|c|c|c|c|c|c|c|c|c|c|c|c|c|}
\hline & & EV & TE & ES & AF1 & AF2 & AV & RO & AC1 & AC2 & SO & IC \\
\hline \multirow{3}{*}{$\begin{array}{l}\text { Conforto } \\
\text { térmico } \\
\left({ }^{\circ} \mathrm{C}\right)\end{array}$} & $\mathrm{X}$ & $23,8 \mathrm{a}$ & $24,3 \mathrm{a}$ & $24,5 \mathrm{a}$ & $25,6 \mathrm{~b}$ & $25,2 \mathrm{~b}$ & $24,4 \mathrm{a}$ & $24,2 \mathrm{a}$ & $23,7 \mathrm{a}$ & $23,6 \mathrm{a}$ & $23,8 \mathrm{a}$ & $24,2 \mathrm{a}$ \\
\hline & S & 1,7 & 2,1 & 1,6 & 1,8 & 1,7 & 1,5 & 1,5 & 1,4 & 1,4 & 1,6 & 1,7 \\
\hline & $\mathrm{N}$ & 1,5 & 2,1 & 1,2 & 1,4 & 1,2 & 1 & 1,1 & 1 & 1 & 1,3 & 1,3 \\
\hline \multirow{3}{*}{$\begin{array}{l}\text { Ventilação } \\
(\mathrm{m} / \mathrm{s})\end{array}$} & $\mathrm{X}$ & $0,4 \mathrm{c}$ & $0,4 \mathrm{~d}$ & $0,4 \mathrm{c}$ & $0,4 \mathrm{c}$ & $0,4 \mathrm{~d}$ & $0,5 \mathrm{~d}$ & $0,4 \mathrm{c}$ & $0,4 \mathrm{~d}$ & $0,5 \mathrm{~d}$ & $0,2 \mathrm{a}$ & $0,4 \mathrm{~b}$ \\
\hline & $\mathrm{S}$ & 0,3 & 0,3 & 0,3 & 0,2 & 0,3 & 0,2 & 0,2 & 0,3 & 0,3 & 0,2 & 0,3 \\
\hline & $\mathrm{N}$ & 156,4 & 98,0 & 123,7 & 92,1 & 70,9 & 77,0 & 91,4 & 98,1 & 121,0 & 197,0 & 130,9 \\
\hline \multirow{3}{*}{$\begin{array}{l}\text { Iluminância } \\
\text { (Lux) }\end{array}$} & $\mathrm{X}$ & $98,2 \mathrm{~b}$ & $83,3 \mathrm{a}$ & $117,2 \mathrm{~b}$ & $66,6 \mathrm{a}$ & $71,8 \mathrm{a}$ & $103,4 \mathrm{~b}$ & $151,5 \mathrm{c}$ & $252,7 \mathrm{~d}$ & $322,8 \mathrm{e}$ & $171,8 \mathrm{c}$ & $117,8 \mathrm{~b}$ \\
\hline & $\mathrm{S}$ & 36,0 & 37,1 & 81,4 & 35,7 & 34,6 & 51,3 & 64,8 & 99,7 & 109,8 & 118,9 & 53,3 \\
\hline & $\mathrm{N}$ & 36,2 & 53,6 & 130,6 & 77,9 & 62,9 & 66,5 & 49,5 & 42,1 & 31,3 & 129,7 & 55,4 \\
\hline \multirow{3}{*}{$\begin{array}{l}\text { Ruído } \\
(\mathrm{dB}(\mathrm{A}))\end{array}$} & X & 83,6 a & 89,9 e & $94,2 \mathrm{~g}$ & $91,3 \mathrm{f}$ & $93,6 \mathrm{~g}$ & $87,6 \mathrm{~d}$ & $86,6 \mathrm{c}$ & $86,5 \mathrm{c}$ & $85,4 \mathrm{~b}$ & $86,8 \mathrm{c}$ & $90,9 \mathrm{e}$ \\
\hline & $\mathrm{S}$ & 4,7 & 4,3 & 3,2 & 1,9 & 2,8 & 1,8 & 1,7 & 2,4 & 1,6 & 1,5 & 2,0 \\
\hline & $\mathrm{N}$ & 0,8 & 0,6 & 0,3 & 0,1 & 0,2 & 0,1 & 0,1 & 0,2 & 0,1 & 0,1 & 0,1 \\
\hline
\end{tabular}

X: média; S: desvio padrão; N: número mínimo de amostras necessárias; EV: envernizamento; TE: têmpera; ES: esmeril; AF1: área da forjadora 1; AF2: área da forjadora 2; AV: área de viragem; RO: região do orvado; AC1: área de corte 1; AC2: área de corte 2; SO: soldagem; IC: inserção de cabos. As médias seguidas por uma mesma letra, em linha, não diferem a $5 \%$ de significância pelo teste de Scott-Knott.

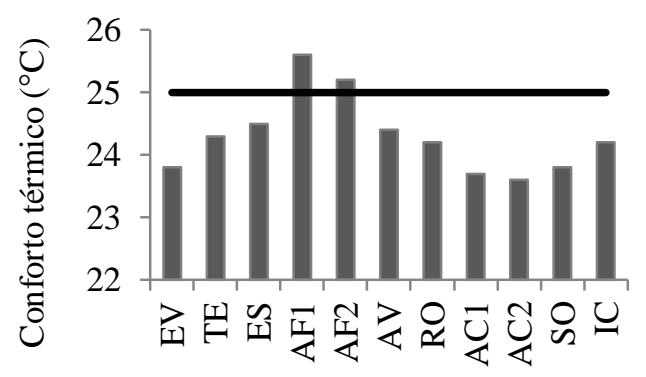

Atividades

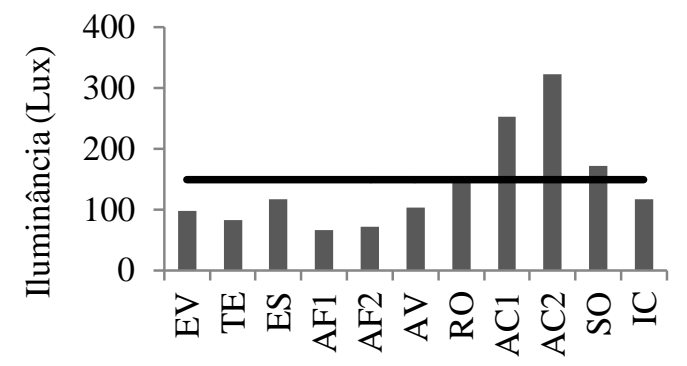

Atividades

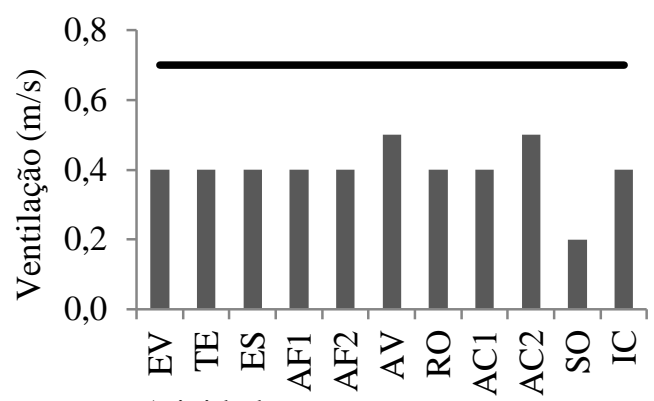

Atividades Limite aceitável

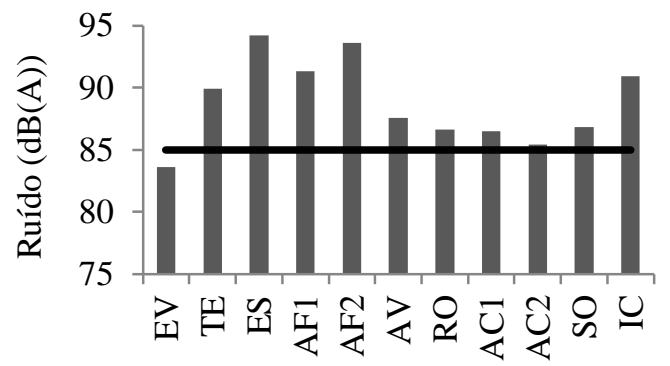

Atividades

Figura 2. Valores médio de IBUTG, ventilação, iluminação e ruído em cada atividade.

Figure 2. Average values of WBGT, ventilation, lighting and noise in each activity. 
Apenas na atividade de envernizamento o nível de ruído estava de acordo com o previsto na NR 15, Anexo $\mathrm{n}^{\mathrm{o}} 1$, Portaria $\mathrm{n}^{\mathrm{o}} 3.214 / 78$, do MTE. O mesmo foi comprovado pelo teste estatístico, e a atividade apresenta conforto durante toda a jornada de trabalho. As outras atividades precisam preferencialmente ser readequadas de acordo com o tempo de exposição permitido ou adotar protetores auriculares.

Com base na disposição original dos postos de trabalho, máquinas e equipamentos dentro do galpão de produção de ferramentas, foi possível fazer o seguinte diagnóstico:

- Normalmente, a máquina de corte 1 é abastecida por longas peças de aço, que são depositadas por um trator na entrada do galpão, e em seguida são levadas à área de corte 2, região de orvado, soldagem e área de viragem. $\mathrm{O}$ arranjo das máquinas das áreas de corte 1 e 2 não favorece a sequência produtiva.

- Nas outras atividades, as máquinas estão dispostas segundo uma sequência lógica de produção. No entanto, na região do orvado, na área de viragem e nas forjadoras, as máquinas estão muito próximas, aumentando o risco de os trabalhadores esbarrarem nas mesmas e sofrerem acidentes, já que nessas atividades é corriqueiro manusear peças em altas temperaturas com pinças manuais.

- O espaçamento entre as máquinas não possibilita a circulação do trabalhador entre elas, de modo que dificulta o abastecimento da matéria-prima que irá ser processada nas etapas de produção.

- As máquinas possuem dimensões diferentes, todas em formato retangular, e, mesmo que em sequência, elas não estão alinhadas. Dessa forma, ao transferir as peças de uma máquina para outra, além de o trabalhador se movimentar lateralmente, ele necessita deslocar-se para a frente ou para trás, executando, assim, movimentos desnecessários, que resultam em baixa eficiência operacional.

- Na têmpera, as mesas onde são armazenadas as peças prontas não possuem um ordenamento correto, atrapalhando a fase anterior da área das forjadoras 1 e 2 .

- No esmeril, onde trabalham dois operadores por máquina, a disposição das máquinas em linha e na extremidade do galpão favorece que os resíduos e as fagulhas sejam direcionados para fora do galpão. Assim, a mesa colocada à frente de cada esmeril facilita a deposição das peças prontas, mas as mesas dispostas ao redor das máquinas não favorecem a movimentação dos trabalhadores.

- A área de envernizamento é composta por três mesas e sua orientação não favorece o processo produtivo. A mesa de inserção de cabos encontra-se na área central do galpão, prejudicando o fluxo de produção da empresa.

A figura 3 indica o layout original e a figura 4 o novo galpão de produção de ferramentas da empresa avaliada.
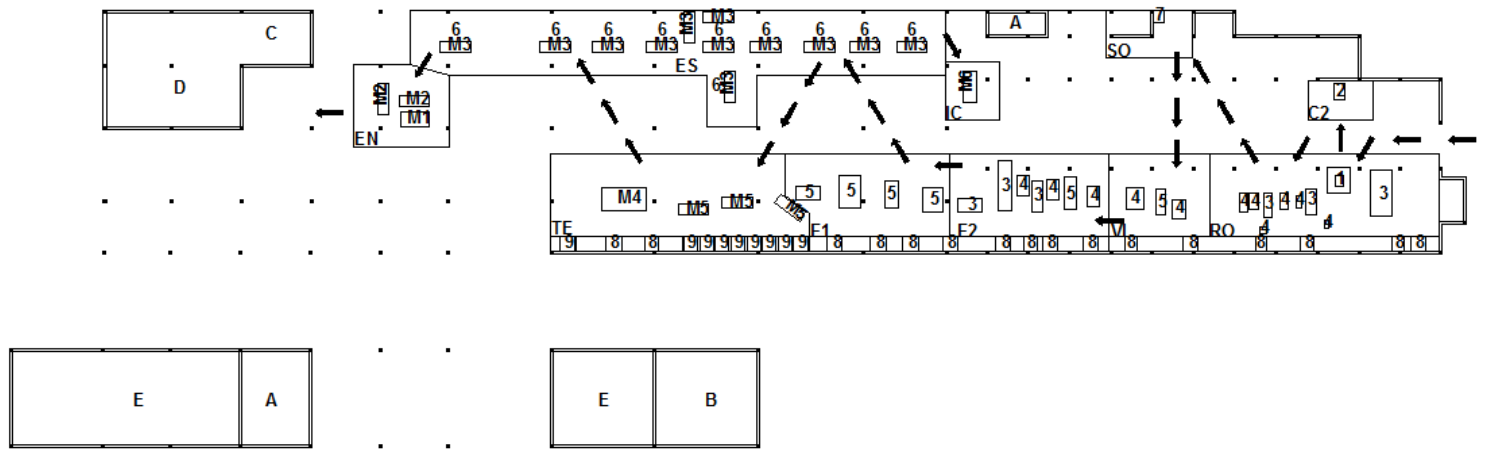

Figura 3. Planta baixa do layout original do galpão de produção de ferramentas.

Figure 3. Original layout of the floor plan of the production tools building.

Legenda: C1: área de corte 1; C2: área de corte 2; RO: região de orvado; VI: área de viragem; F1: área da forjadora 1; F2: área da forjadora 2; TE: têmpera; IC: inserção de cabos; ES: esmeril; EN: envernizamento; SO: soldagem; M1: mesa de envernizamento 1; M2: mesa de envernizamento 2; M3: mesa do esmeril; M4: reservatório de óleo; M5: mesa da têmpera; M6: mesa de inserção de cabos; A: banheiro; B: almoxarifado; C: escritório; D: depósito de matéria-prima; E: depósito de ferramentas; 1: máquina de corte 1; 2: máquina de corte $2 ; 3$ : forjadora $1 ; 4$ : prensa; 5 : forjadora $2 ; 6$ : esmeril; 7 : máquina de solda; 8: forno; 9 : têmpera aberta. 
São recomendadas as seguintes intervenções:

- As máquinas das áreas de corte 1 e 2 devem ser colocadas na mesma área e em sequência. As peças de aço são depositadas ao redor das máquinas de corte, com auxílio de um trator, pela entrada do galpão. Elas são repassadas à região do orvado, soldagem e de volta à área de viragem, favorecendo o fluxo de produção.

- As máquinas da região do orvado, da área de viragem e da área das forjadoras 1 e 2 devem ser organizadas de forma que haja maior facilidade de transporte manual de peças para abastecimento e escoamento de produção e que possibilite aos operadores das máquinas transitarem lateralmente entre as máquinas durante realização da atividade em que atuam, evitando os desperdícios com movimentos desnecessários.

- $\quad \mathrm{Na}$ atividade da têmpera, as mesas devem ser ordenadas, e as que ficavam na interseção entre a área da marcadora e a têmpera foram alinhadas em menores dimensões, para serem utilizadas na fase de têmpera, a fim de não atrapalhar na área da forjadora 1 e 2.

- Propõe-se a retirada do esmeril que fica isolado no meio do galpão, pois ele atrapalha a movimentação de peças no interior do local, mantendo-se as mesas à frente do esmeril, pois elas servem para acúmulo de peças prontas, eliminando somente as mesas ao redor do esmeril.

- Na posição original, o caminho dos dois envernizadores fica limitado em áreas apertadas, de modo que a reoganização das mesas em "L" facilitará a movimentação dos trabalhadores. Desse modo, na mesa central, os funcionários envernizam as peças e, nas laterais, depositam as ferramentas prontas.

- Sugere-se transferir a mesa de inserção de cabos para o lado da mesa de envernizamento. Assim ela ficará mais perto do local de armazenamento, reduzindo-se os níveis de ruído e favorecendo o conforto térmico aos funcionários, pela maior distância entre a mesa e o forno.

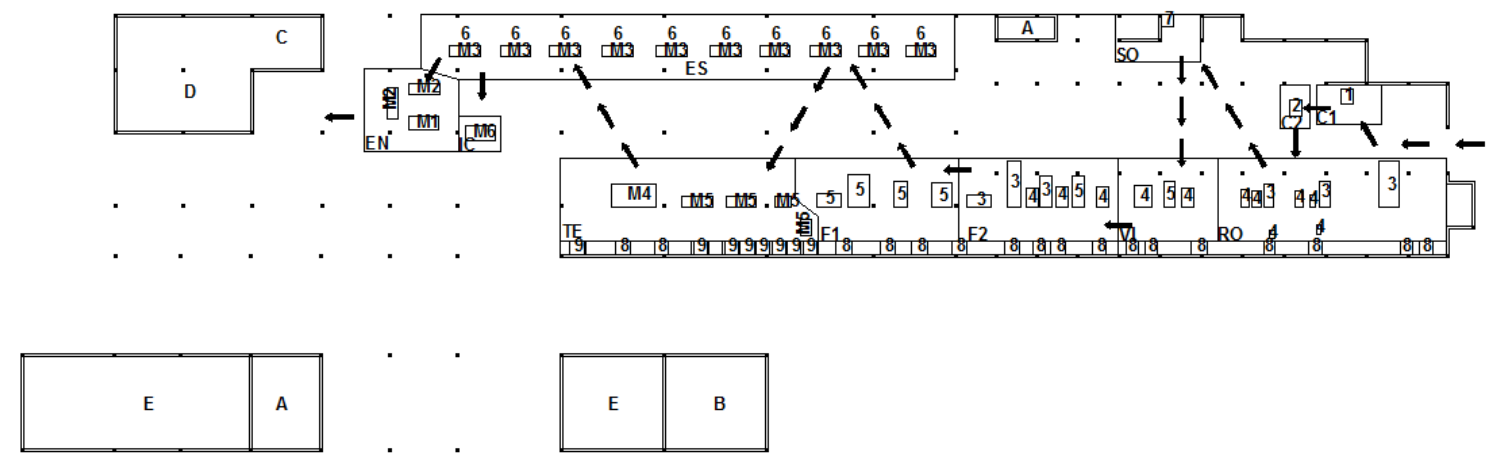

Figura 4. Planta baixa do novo galpão de produção de ferramentas.

Figure 4. Floor plan of the new production tools building.

Legenda: C1: área de corte 1; C2: área de corte 2; RO: região de orvado; VI: área de viragem; F1: área da forjadora 1; F2: área da forjadora 2; TE: têmpera; IC: inserção de cabos; ES: esmeril; EN: envernizamento; SO: soldagem; M1: mesa de envernizamento 1; M2: mesa de envernizamento 2; M3: mesa do esmeril; M4: reservatório de óleo; M5: mesa da têmpera; M6: mesa de inserção de cabos; A: banheiro; B: almoxarifado; C: escritório; D: depósito de matéria-prima; E: depósito de ferramentas; 1: máquina de corte 1; 2: máquina de corte $2 ; 3$ : forjadora $1 ; 4$ : prensa; 5 : forjadora $2 ; 6$ : esmeril; 7: máquina de solda; 8: forno; 9: têmpera aberta.

\section{CONCLUSÕES}

- As áreas das forjadoras 1 e 2 apresentaram valores de IBUTG acima do permitido para que a atividade se proceda continuamente. $O$ trabalho nessas áreas deve acontecer por 45 minutos, descansando-se por 15 minutos, para adequação ao conforto térmico. Nas outras atividades, o trabalho pode ser realizado continuamente durante toda a jornada de trabalho.

- A velocidade do vento em todas as atividades não oferece riscos à saúde do trabalhador ao desenvolver as atividades de produção de ferramentas.

- Apenas a região do orvado, área de corte 1 e soldagem apresentaram níveis de iluminância dentro do permitido (NR-15). Deve-se, assim, aumentar os pontos de iluminação dentro do galpão nessas 
regiões e, se ainda permanecer a baixa iluminância, adotar a iluminação artificial específica sobre a atividade.

- Apenas o envernizamento apresentou níveis de ruído dentro do tolerável. Todas as outras atividades extrapolaram os níveis toleráveis para a atividade, sendo imprescindível utilizar protetor auricular para execução das atividades. No novo layout proposto, ao se aumentar a distância entre máquinas, reduz-se o efeito dos ruídos produzidos pela proximidade entre elas.

\section{REFERÊNCIAS}

ASSOCIAÇÃO NACIONAL DAS ÁGUAS (ANA). Hidroweb: sistema de informações hidrológicas. Disponível em: <http://hidroweb.ana.gov.br>. Acesso em: 14/05/2010.

ASSOCIAÇÃO BRASILEIRA DE NORMAS TÉCNICAS (ABNT). NBR 5413: Iluminância de Interiores. Rio de Janeiro, 1992. 13 p.

CONAW, P. L. Estatística. São Paulo: Edgard Blucher, 1977. 264 p.

CORREA, H. L.; CORREA, C. A. Administração de produção e operações: manufatura e serviços: uma abordagem estratégica. 2. ed. São Paulo: Atlas, 2008. 690 p.

FIEDLER, N. C.; GUIMARÃES, P. P.; ALVES, R. T.; WANDERLEY, F. B. Avaliação ergonômica do ambiente de trabalho em marcenarias no sul do Estado do Espírito Santo. Revista Árvore, Viçosa, v. 34, n. 5, p. $907-915,2010$.

GUIMARÃES, P. P. Fatores ergonômicos das atividades em uma fábrica de ferramentas. $83 \mathrm{f}$. Dissertação (Mestrado em Ciências Florestais) - Universidade Federal do Espírito Santo. Jerônimo Monteiro, ES, 2011.

MARMARAS, N.; NATHANAEL, D. Workplace design. In: SALVENDY, G. Handbook of human factors and ergonomics. Indiana, United States of America: John Wiley e Sons, 2006, cap. 22, p. 575 589.

NORMA REGULAMENTADORA - NR 15. Atividades e operações insalubres. In: Segurança e medicina do trabalho. 61. ed. São Paulo: Atlas, p. 138 - 220, 2007.

NORMA REGULAMENTADORA - NR 17. Ergonomia. In: Segurança e medicina do trabalho. 61. ed. São Paulo: Atlas, p. 232 - 245, 2007.

SEGURANÇA E MEDICINA DO TRABALHO. Manuais de Legislação. Portaria n. 3.214/78 do Ministério do Trabalho. 63 ed. São Paulo: Atlas, 2009. 799 p.

SILVA, K. R.; SOUZA, A. P.; MINETTI, L. J. Avaliação do perfil de trabalhadores e das condições de trabalho em marcenarias no município de Viçosa, MG. Revista Árvore, v. 26, n. 6, p. 769 - 775, 2002.

TORTORELLA, G. L.; FOGLIATTO, F. S. Planejamento sistemático de layout com apoio de análise de decisão multicritério. Produção, São Paulo, v. 18, n. 3, p. 609 - 624, 2008.

VASCONCELOS, C. S. F.; VILLAROUCO, V.; SOARES, M. M. Avaliação ergonômica do ambiente construído: estudo de caso em uma biblioteca universitária. Revista Ação Ergonômica, Rio de Janeiro, v. 4 ; n. 1 , p. 5 - 25, 2009. 
